\title{
In women with incontinence, the need for pressure-flow study before surgery and abnormalities in the voiding phase. An up-to-date comment on the available problem accompanied by literature
}

\author{
Kutluhan Erdem, Alper Cosskun, Fatih Üstün, Fatih Tarhan \\ Department of Urology, University of Health Sciences, Kartal Dr. Lutfi Kurdar City Hospital, Istanbul, Turkey
}

\begin{abstract}
Summary $\quad$ Objective: To investigate the differences between urodynamic findings and history in women with urinary incontinence before surgery and clarify the need for preoperative pressure-flow studies.

Materials and methods: The medical records of 1018 women who underwent urodynamic examination for urinary incontinence between 2010 and 2015 were evaluated retrospectively. Stress $(n=442)$, urge $(n=334)$ and mixed $(n=242)$ were classified as type urinary incontinence according to urodynamics. The voiding phase findings of the patients were examined. Results: The mean age of the patients was $47.85 \pm 0.27$ years. $18.4 \%$ of patients $(n=187)$ had voiding phase problems. Furthermore, this condition was seen in the most urge incontinence type urinary incontinence (35\%). There was a statistically significant difference between the groups' voiding phase findings $(p<0.0001)$. The relationship between the patient's history and international consultation on incontinence questionnaire form scoring (ICIQ) and the urodynamics results showed no excellent correlation.

Conclusions: Voiding phase abnormalities are not uncommon in patients with urinary incontinence. They should be considered in the evaluation of patients. Voiding phase findings may show significant differences between urodynamic data and history.

Besides, the data obtained with the questionnaire forms were significantly different from the findings obtained by urodynamics. Consequently, urodynamics may change pre-operative clinical decision.
\end{abstract}

KEY WORDS: Urinary incontinence; Urodynamics; Voiding.

Submitted 28 February 2021; Accepted 14 June 2021

\section{INTRODUCTION}

Urinary incontinence is a common health condition that can affect about $50 \%$ of adult women and decrease life quality (1). This condition increases with age. Ten to twenty percent of women and up to $77 \%$ of women residing in nursing homes have urinary incontinence, yet only $25 \%$ attempt or receive treatment (2).

In the evaluation of incontinence patients, the history alone may be insufficient to diagnose and classification. Understanding lower urinary tract function and revealing the underlying pathophysiology is essential for the evalu- ation of these patients. Hence the information gained from urodynamics may help us. Performing urodynamics is controversial before surgical treatment of stress urinary incontinence (SUI) (3). According to the Cochrane library, urodynamics can change the clinical decision (4).

The NICE (National Institute for health and care excellence) guideline recommends urodynamic examination before stress urinary incontinence surgery (5). EAU guidelines do not recommend routinely carrying out urodynamics when offering treatment for uncomplicated urinary incontinence (6).

Incontinence mostly develops as a result of urine storage dysfunction and the incidence of bladder outlet obstruction (BOO) is low. For this reason, in daily practice, the only cystometry is usually performed in addition to history and physical examination. Since pressure-flow studies (PFS) are generally not implemented, the diagnosis of urinary voiding dysfunctions can be overlooked. Thus redundant surgical procedures and improper treatments can be applied to these patients.

To clarify whether SUI patients are always pure SUI and if these patients should be submitted to urodynamic before surgery to prevent incorrect surgical approach, we aimed to retrospectively investigate the abnormalities in the voiding phase of female patients who have undergone PFS for incontinence.

\section{Materials AND METHOdS}

Between January 2010 and June 2015, 1329 female patients aged 18-60 who had incontinence for at least six months and underwent urodynamics were evaluated retrospectively. Neurogenic lower urinary system dysfunction, active urinary infection, bladder stone, urethral stricture, pelvic radiation, pelvic surgery history, and patients who could not perform micturition in PFS were excluded from the study (311 patients).

Patients' demographic properties, urination diary, pad test, urine analysis and culture, urethral mobility (Q tip), urinary ultrasonography, post-voided residue, and urodynamic examination findings were retrieved. At filling cystometry, urinary incontinence triggered with Valsalva or coughing was accepted as stress type urinary inconti-

No conflict of interest declared. 
nence, involuntary and inhibited detrusor contractions as urge urinary incontinence and the presence of both findings as mixed urinary incontinence.

At PFS, the inability of contraction at sufficient force or continuity resulting in prolonged or insufficient bladder discharge was considered underactive detrusor, $\mathrm{Q}_{\max }>12$ $\mathrm{ml} / \mathrm{sec}$ and $\mathrm{Pdet} \mathrm{Q}_{\max }>20 \mathrm{~cm} \mathrm{H}_{2} \mathrm{O}$ was considered as $\mathrm{BOO}$. Voiding characterized by an intermittent or staccato flow pattern due to involuntary and irregular pelvic floor contractions in neurologically healthful patients was evaluated as dysfunctional voiding $(7,8)$.

The patients were grouped as stress, urge, and mixed type urinary incontinence. Whether the voiding phase findings of the patients were normal or abnormal was checked. Urodynamics was applied according to the International Continence Association (ICS) (4).

Chi-square test was utilized to evaluate the results with Prism 5.0 (GraphPad, USA) program. P value $<0.05$ was accepted as statistically significant.

\section{RESULTS}

The average age of the patients was $47.85 \pm 0.27$ years. Of the patients, 442 (43\%) were evaluated as stress-type, $334(32 \%)$ as urge-type, and 242 (25\%) as mixed-type incontinence (Figure 1). Urethral stricture was diagnosed in $6 \%(\mathrm{n}=11)$ of those with excretory phase problems, dysfunctional voiding in $51 \%(\mathrm{n}=96)$ and underactive detrusor in 43\% ( $n=80)$. Urethral stricture and dysfunctional voiding and the rate of underactive detrusor were higher in patients with urge-type urinary incontinence. (47\%) (Table 1).

Another finding was lack of good correlation between history and urodynamic filling phase results (Table 2). Similarly, data from International Consultation on Incontinence Questionnaire form (ICIQ) and findings from urodynamics are not fully concordant. There are considerable differences, especially in mixed urinary incontinence (Table 3).

Figure 1.

Incontinence types and percentages.

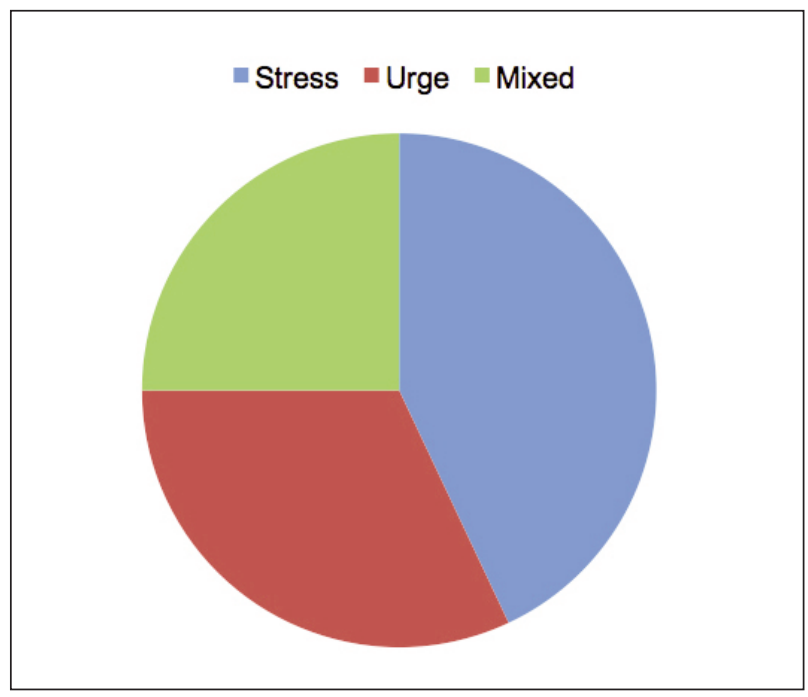

Table 1.

The voiding phase findings detected in the PFS.

\begin{tabular}{|l|l|c|c|}
\hline Groups & Voiding phase findings & (n) & (\%) \\
\hline Stress urinary incontinence $(\mathrm{n}=442)$ & Normal & 403 & 91 \\
& Urethral stricture & 0 & 0 \\
& Dysfunctional voiding & 15 & 3 \\
& Underactive detrusor & 24 & 6 \\
\hline Urge type urinary incontinence $(\mathrm{n}=334)$ & Normal & 216 & 65 \\
& Uretral stricture & 9 & 3 \\
& Dysfunctional voiding & 71 & 21 \\
& Underactive detrusor & 38 & 11 \\
\hline Mixed type urinary incontinence $(\mathrm{n}=242)$ & Normal & 212 & 88 \\
& Uretral stricture & 2 & 1 \\
& Dysfunctional voiding & 10 & 4 \\
& Underactive detrusor & 18 & 7 \\
\hline PFS: Pressure-flow study. & \multicolumn{3}{|l}{} \\
\hline
\end{tabular}

Table 2.

Comparison of anamnesis and filling phase findings.

\begin{tabular}{|c|c|c|c|}
\hline Anamnesis & Filling phase & (n) & $(\%)$ \\
\hline SUI $(n=148)$ & $\begin{array}{l}\text { SUI } \\
\text { UUI } \\
\text { MUI }\end{array}$ & $\begin{array}{l}(69) \\
(37) \\
(42)\end{array}$ & $\begin{array}{l}47 \\
25 \\
28\end{array}$ \\
\hline $\operatorname{UUI}(n=120)$ & $\begin{array}{l}\text { SUI } \\
\text { UUI } \\
\text { MUI }\end{array}$ & $\begin{array}{l}(46) \\
(44) \\
(30)\end{array}$ & $\begin{array}{l}38 \\
37 \\
25\end{array}$ \\
\hline$\overline{\mathrm{MUI}}(\mathrm{n}=750)$ & $\begin{array}{l}\text { SUI } \\
\text { UUI } \\
\text { MUI }\end{array}$ & $\begin{array}{l}(326) \\
(266) \\
(172)\end{array}$ & $\begin{array}{l}43 \\
35 \\
22\end{array}$ \\
\hline
\end{tabular}

Table 3.

Comparison of ICIQ and filling phase findings.

\begin{tabular}{|l|l|c|c|}
\hline Anamnesis & Filling phase & (n) & (\%) \\
\hline SUI $(n=123)$ & SUI & $(60)$ & 49 \\
& UUI & $(31)$ & 25 \\
& MUI & $(32)$ & 26 \\
\hline UUI $(n=116)$ & SUI & $(50)$ & 43 \\
& UUI & $(40)$ & 35 \\
& MUI & $(26)$ & 22 \\
\hline MUI $(n=779)$ & SUI & $(325)$ & 42 \\
& UUI & $(271)$ & 35 \\
& MUI & $(183)$ & 23 \\
\hline SUI: Stress urinary incontinence; UUI: Urǵe urinary incontinence; MUI: Mixed urinary incontinence; \\
ICIQ: International consultation on incontinence questionnaire form.
\end{tabular}

\section{Discussion}

The bladder should be able to store urine at low pressure and at an appropriate volume, discharge the stored urine at once, and coordinate detrusor contraction and sphincter relaxation during voiding.

The knowledge regarding the togetherness of urinary voiding dysfunctions in female patients with incontinence in the literature is unclear. In $18.4 \%(n=187)$, we found that patients with incontinence also have voiding phase problems simultaneously. Additionally urethral stricture was found in $6 \%(\mathrm{n}=11)$, dysfunctional voiding in $51 \%$ ( $n=96)$, and underactive detrusor in $43 \%(n=80)$ of these patients. We established that our outcomes were consistent with the literature (7). 
If we come to underactive detrusor, we see that there are not enough studies and accepted objective criteria in female patients regarding underactive detrusor.

The existing nomograms about underactive detrusor have been used to describe male voiding dysfunction (8).

We defined that there were $7.9 \%(n=80)$ underactive detrusor our patients.

Estimating the prevalence of $\mathrm{BOO}$ in women with incontinence is problematic in light of the existing literature. A nomogram has been developed to diagnose $\mathrm{BOO}$ in women. However, due to the disparities in the pathophysiology of voiding problems compared to men, it has not been widely accepted, especially among urologists interested in this topic. Even so, it is possible to determine female bladder outlet obstruction with the support of pressure-flow studies and clinical symptoms simultaneously with video-urodynamics (8). It has been seen that even if in women with voiding difficulties and low urinary flow symptoms, the correlation between symptoms and urodynamics objective BUO is low, and it is not easy to reach a diagnosis in this way $(9,10)$. Another clinical entity that should be kept in mind is the possibility of the development of detrusor overactivity secondary to bladder outlet obstruction (7). As a matter of fact, in our study, the most common storage problem in patients with outflow obstruction was found to be urge type urinary incontinence. In addition, urethral stricture was found in $1.1 \%$ of the patients.

Although dysfunctional voiding is primarily diagnosed in the pediatric age group, it is one of the most common urinary voiding dysfunctions in women with lower urinary tract symptoms. In the literature, dysfunctional voiding was established in women with lower urinary tract symptoms and urodynamic examination with a rate of 9.6-12\% $(11,12)$. Similarly, we noticed dysfunctional voiding was at a rate of $9.4 \%$ in our study.

It is a broad-spectrum non-neurogenic disorder involving dysfunction of the lower urinary tract and intestinal tract. Also, it is one of the most common urinary voiding dysfunctions in women with lower urinary tract symptoms. We presented treatment options such as behavioral therapy (pelvic floor physiotherapy, biofeedback), medical therapy, cognitive therapy and sacral neuromodulation to patients who were diagnosed with this dysfunctional voiding

Urodynamics after evaluation in the outpatient clinic changes the diagnosis by $57 \%$ and the choice of the treatment plan by $14 \%$, and canalizes the surgical procedure (13-16). The best indicator for this is that $40 \%$ of overactive bladder patients are diverted for stress urinary surgery $(8,17)$. In another study, it has been indicated that the voiding phase is the most commonly used method to modify the surgical procedure in overactive bladder and intrinsic urinary sphincter deficiency (13).

In our study, we found out that the diagnosis changed in $18.4 \%$ of patients after PFS. Thus, we think that unnecessary surgery in 69/684 (10\%) patients and inappropriate medical treatment in $47 / 334$ (14\%) patients with urinary incontinence have been prevented.

Limitations of our study are being a single-center study with retrospective design, lack of Overactive Bladder Questionnaire (OABQ) and ICIQ scoring in statistical data, no follow-up of the patients after surgery. Another matter of criticism could be that evaluations were not made by a single physician. We also admit that our results do not support a new finding, but we believe that our study with a high number of patients may contribute to clarify the controversial topic of necessity to perform urodynamics before surgery.

\section{Conclusions}

Urodynamics can provide clinicians with detailed and useful information about lower urinary tract function that may affect medical and surgical decisions. We recommend performing pressure-flow studies together with cystometry not to overlook the diagnosis of possible urinary voiding dysfunction in female patients with incontinence undergoing urodynamic examination. We believe that supporting these data with multi-center and prospective studies will significantly contribute to the literature.

\section{REFERENCES}

1. Minassian VA, Stewart WF, Wood GC. Urinary incontinence in women: variation in prevalence estimates and risk factors. Obstet Gynecol. 2008; 111:324-331.

2. Tennstedt SL, Link CL, Steers WD, McKinlay JB. Prevalence of and risk factors for urine leakage in a racially and ethnically diverse population of adults: the Boston Area Community Health (BACH) Survey. Am J Epidemiol. 2008; 167:390-399.

3. Fletcher SG, Lemack GE. Clarifying the role of urodynamics in the preoperative evaluation of stress urinary incontinence. Scientific World Journal. 2008; 25:1259-1268.

4. Glazener CM, Lapitan MC. Urodynamic studies for management of urinary incontinence in children and adults. Cochrane Database Syst Rev. 2012; 18: CD003195.

5. Urinary Incontinence: The management of urinary incontinence in women. NICE Clinical Guideline 40. London, United Kingdom: National Institute for Health and Clinical Excellence, 2006.

6. Burkhard FC, Bosch JLHR, Cruz F, et al. EAU urinary incontinence guidelines 2018 ISBN 978-94-92671-07-3.

7. Yenilmez A, Turgut M, Dönmez T, Özyürek Y. Idrar kaçıran kadın hastalarda basınç-akım çalısmasının (BAÇ) Önemi. Turk J Urol. 2004; 30:451-456.

8. Onyishi SE, Twiss CO. Pressure flow studies in men and women. Urol Clin North Am. 2014; 41:453-67.

9. Groutz A, Blaivas JG, Chaikin DC. Bladder outlet obstruction in women: Definition and characteristics. Neurourol Urodyn 2000; 19:213-220.

10. Groutz A, Gordon D, Lessing JB, Wolman I, Jaffa A, David MP. Prevalence and characteristics of voiding difficulties in women: Are subjective symptoms substantiated by objective urodynamic data? Urology. 1999; 54: 268-272.

11. Carlson KV, Fiske J, Nitti VW. Value of routine evaluation of the voiding phase when performing urodynamic testing in women with lower urinary tract symptoms. J Urol. 2000; 164:1614-1618.

12. Nitti VW, Tu LM, Gitlin J. Diagnosing bladder outlet obstruction in women. J Urol. 1999; 161:1535-1540

13. Sirls LT, Richter HE, Litman HJ, et al. The effect of urodynamic testing on clinical diagnosis, treatment plan and outcomes in women 
undergoing stress urinary incontinence surgery. J Urol. 2013; 189 : 204-209.

14. Adelowo A, Dessie S, Rosenblatt L. The role of preoperative urodynamics in urogynecologic procedures. J Minim Invasive Gynecol. 2014; 21:217-222.

15. Serati M, Cattoni E, Siesto G, et al. Urodynamic evaluation: can it prevent the need for surgical intervention in women with apparent pure stress urinary incontinence? BJU Int. 2013; 112:344-350.
16. Rachaneni S, Latthe P. Does preoperative urodynamics improve outcomes for women undergoing surgery for stress urinary incontinence? A systematic review and meta-analysis. BJOG. 2015; 122:816.

17. van Leijsen SAL, Hoogstad-van Evert JS, J Mol BW, et al. The correlation between clinical and urodynamic diagnosis in classifying the type of urinary incontinence in women. A systematic review of the literature. Neurourol Urodyn. 2011; 30:495-502.

\section{Correspondence}

Kutluhan Erdem, MD

kutluhan1988@gmail.com

Alper Coşkun, MD

dr.alper05@gmail.com

Fatih Üstün, MD

drfatihustun@gmail.com

Fatih Tarhan, MD

tarhanf@yahoo.com

Department of Urology, University of Health Sciences, Kartal Dr. Lutfi Kirdar City Hospital, Istanbul (Turkey) 